\title{
Spectral classification of short numerical exon and intron sequences
}

\author{
Benjamin YM Kwan ${ }^{1 *}$, Jennifer YY Kwan², Hon Keung Kwan ${ }^{3}$ \\ From Seventh International Society for Computational Biology (ISCB) Student Council Symposium 2011 \\ Vienna, Austria. 15 July 2011
}

\begin{abstract}
This research presents three new numerical representations for classifying short exon and intron sequences using discrete Fourier transform period-3 value. Based on the human genome, results indicate that the Complex TwinPair representation is attractive compared with other numerical representations and the approach has potential applications in genome annotation and read mapping.
\end{abstract}

\section{Background}

Current methods for genome annotation focus on sequence similarity or motif matching to known genes and there is a need for a complementary or more effective approach. It is known that protein coding (exonic or $\mathrm{C}-\mathrm{G}$ rich) regions exhibit a period-3 property which is less prominent in noncoding (intronic or A-T rich) regions. The boundary between these 2 regions becomes less apparent as sequence length becomes shorter. The period-3 property is likely due to the 3-base-length of codons. $\mathrm{C}-\mathrm{G}$ rich content in coding regions is due to nonuniform codon usage. For spectral analysis of period-3 value, a nucleotide sequence has to be converted to a numerical sequence. The choice of numerical representation affects how well its biological properties can be preserved and reflected.

\section{Methodology}

Based on exon and intron sequences downloaded from UCSC Genome Browser on Human (GRCh37/hg19) (http://genome.ucsc.edu/cgi-bin/hgText) using [1-3], the classification performance in precisions (\%) were computed by applying the spectral analysis and thresholding of [4] to the following twelve numerical representation methods: 1. Integer Number; 2. Single Galois Indicator; 3. Paired Nucleotide Atomic Number; 4. Atomic Number; 5. Molecular Mass; 6. EIIP; 7. Paired Numeric; 8.

\footnotetext{
* Correspondence: bkwan066@uottawa.ca

${ }^{1}$ Faculty of Medicine, University of Ottawa, Ottawa, Ontario K1H 8MS, Canada Full list of author information is available at the end of the article
}

Real Number; 9. Complex Number; 10. Complex TwinPair $(C, G=-1 ; A, T=j) ; 11$. Complex Bipolar-Pair Code I $(C=-1 ; G=1 ; A=j ; T=-j) ; 12$. Complex Bipolar-Pair Code II $(C=-1 ; G=1 ; A=-j ; T=j)$. Methods 1-9 are specified in [4] and Methods 10-12 are new

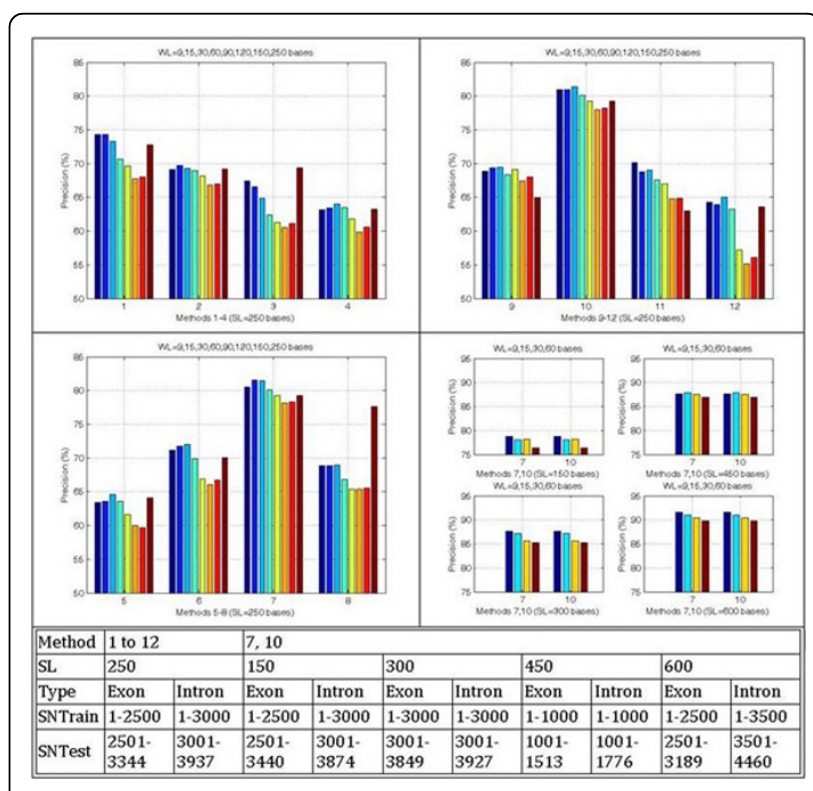

Figure 1 Precisions of methods obtained by different WL set and SL (SL: Sequence length in bases; WL: Window length in bases; SNTrain: Sequence numbers for training; SNTest: Sequence numbers for testing).

\section{C)

( 2011 Kwan et al; licensee BioMed Central Ltd. This is an open access article distributed under the terms of the Creative Commons Attribution License (http://creativecommons.org/licenses/by/2.0), which permits unrestricted use, distribution, and reproduction in any medium, provided the original work is properly cited. 
numerical representations. In simulations, two adjacent windows are overlapped by 3 bases.

\section{Results and conclusions}

The results summarized in Figure 1 indicate that the approach is capable for effective classification of untrained short exon and intron sequences. Among the 3 new numerical representations, the Complex TwinPair (Method 10) achieves a precision of about $79 \%$ to $92 \%$ for a sequence length of 150 bases to 600 bases and a window length of 9 bases which is comparable with those of the Paired Numeric (Method 7).

\section{Author details}

${ }^{1}$ Faculty of Medicine, University of Ottawa, Ottawa, Ontario K1H 8MS,

Canada. 'School of Medicine, Queen's University, Kingston, Ontario K7L 3N6, Canada. ${ }^{3}$ Department of Electrical \& Computer Engineering, University of

Windsor, Windsor, Ontario N9B 3P4, Canada.

Published: 21 November 2011

\section{References}

1. Karolchik D, Hinrichs AS, Furey TS, Roskin KM, Sugnet CW, Haussler D, Kent WJ: The UCSC Table Browser data retrieval tool. Nucleic Acids Res 2004, 32(Database issue):D493-496.

2. Goecks J, Nekrutenko A, Taylor J: Galaxy: a comprehensive approach for supporting accessible, reproducible, and transparent computational research in the life sciences. Genome Biol 2010, 11(8):R86.

3. Blackenberg D, Von Kuster G, Coraor N, Ananda G, Lazarus R, Mangan M, Nekrutenko A, Taylor J: Galaxy: a web-based genome analysis tool for experimentalists. Curr Protoc Mol Biol 2010, Chapter 19(Unit 19.10):1-21.

4. Kwan JYY, Kwan BYM, Kwan HK: Spectral analysis of numerical exon and intron sequences. Proceedings of IEEE International Conference on Bioinformatics and Biomedicine Workshops (BIBMW) Hong Kong; 2010, 876-877.

doi:10.1186/1471-2105-12-S11-A13

Cite this article as: Kwan et al:: Spectral classification of short numerical exon and intron sequences. BMC Bioinformatics 2011 12(Suppl 11):A13.

\section{Submit your next manuscript to BioMed Central} and take full advantage of:

- Convenient online submission

- Thorough peer review

- No space constraints or color figure charges

- Immediate publication on acceptance

- Inclusion in PubMed, CAS, Scopus and Google Scholar

- Research which is freely available for redistribution

Submit your manuscript at www.biomedcentral.com/submit
C Biomed Central 